\title{
A Meta-Analysis of hope enhancement strategies in clinical and community settings
}

Robert Weis ${ }^{{ }^{*}}$ and Elena C Speridakos ${ }^{2}$

\footnotetext{
* Correspondence: weisr@denison. edu

'Department of Psychology, Granville, Ohio, 43023, USA Full list of author information is available at the end of the article
}

\begin{abstract}
Background: The last two decades have seen the development of theoretical models of hope, which have greatly influenced the field of positive psychology and the study of well-being. Recently, there has been increased interest in using these theories to create interventions and other strategies to enhance hopefulness among clinic-referred individuals and members of the community. We used meta-analysis to determine whether these hope enhancement strategies were associated with (a) increased hopefulness, (b) improved life satisfaction, and (c) decreased psychological distress among participants.

Results: Analysis of 27 studies involving 2, 154 participants showed significant, but small, effect sizes for hopefulness and life satisfaction and no overall relationship between hope enhancement strategies and decreased psychological distress. Moderation tests indicated greater effect sizes for studies involving brief interventions, conducted in laboratory settings, and administered to students or individuals recruited from the community. Results also suggested publication bias.

Conclusions: As the current study provides only modest evidence for the ability of hope enhancement strategies to increase hopefulness or life satisfaction and no consistent evidence that hope enhancement strategies can alleviate psychological distress., traditional psychotherapeutic interventions or other effective positive psychological constructs (e.g., gratitude, optimism, mindfulness) might best be targeted in applied settings.
\end{abstract}

Keywords: Hope theory, hope enhancement, hope therapy, positive psychological interventions

A Meta-Analysis of Hope Enhancement Strategies in Clinical and Community Settings Hope has long been recognized as an important component of psychological growth and change Freud (1905/1968). believed that many of the benefits of psychoanalysis could be explained by patients' "expectations, colored by hope and faith" in the treatment process (p. 289). Later, Menninger (1959) urged mental health practitioners to study hope, “a basic but elusive ingredient in our daily work” (p. 281). Like Freud, Menninger suggested that many psychotherapeutic gains might be attributable to increased hope during the course of treatment. Subsequent theorists have extended his assertion, giving hope a central role in therapy. For example, Frank (1971) described patients as demoralized individuals who lacked hope. He argued that the "arousal of the patient's hope" was common to all psychological treatments, and necessary to

\section{Springer}

(C) 2011 Weis and Speridakos; licensee Springer. This is an Open Access article distributed under the terms of the Creative Commons Attribution License (http://creativecommons.org/licenses/by/2.0), which permits unrestricted use, distribution, and reproduction in any medium, provided the original work is properly cited. 
alleviate suffering (p. 357). Similarly, Yalom (1995) described the instillation of hope as crucial to any therapy-an essential component necessary for clients to initiate and sustain their involvement in the therapeutic process over time.

\section{Hope Theories}

The last two decades have witnessed the development of a theoretical model of hope which has greatly influenced researchers in the field of positive psychology. Rather than emphasizing the emotional aspects of hopefulness, C.R. Snyder conceptualized hope as a cognitive construct which reflects people's motivation and capacity to strive toward personally-relevant goals (Snyder, 1994; Snyder, Rand, \& Sigmon, 2002). Hope depends on two cognitions in particular: agency thinking and pathways thinking. Agency thinking refers to people's perceived ability to pursue goals despite obstacles and is evident in self-statements such as, "I can do this" and "I am not going to be stopped." Pathways thinking refers to people's perceived ability to generate plausible routes toward goals and is evident in self-statements such as "I can find a way to get this done." Considerable research has supported the notion that hope is dependent on both agency and pathways thinking, that these components of hope can be validly measured, and that hopeful individuals enjoy many benefits not experienced by their low-hope counterparts including superior academic achievement, psychological adjustment, and physical health (Arnau et al., 2010; Snyder, Sympson, Michael, \& Cheavens, 2001).

Recently, Snyder's (1994) general model for hope has been applied to psychotherapy (Cheavens, Feldman, Woodward, \& Snyder, 2006; Lopez, Snyder, Magyar-Moe, Edwards, Pedrotti, Janowski, et al., 2004; Pedrotti, Edwards, \& Lopez, 2008; Snyder, 2000; Snyder, Feldman, Taylor, Schroeder, \& Adams, 2000; Snyder, Parenteau, Shorey, Kahle, \& Berg, 2002). From this perspective, people seek therapy when they repeatedly encounter barriers to their goals which they cannot circumvent or overcome. These barriers engender negative emotions, such as anxiety, depression, or anger, which are often the proximal determinants of their decision to seek help. The therapist's job is to increase hope by helping clients set clear, objective goals for treatment and increase agency and pathways thinking Snyder and colleagues (2000). have argued that hope is a common factor in psychotherapy: "Psychotherapies 'work' precisely because they enable people to identify goals that represent solutions to their problems, they specify particular routes for reaching those goals (pathways thinking), and they motivate clients to use those routes so as to implement change (agency thinking)" (pp. 257-258).

The application of Snyder's hope theory to psychotherapy has led to the development of specific interventions designed to systematically increase hope in clients. These interventions have several components in common. First, the therapist presents the basic tenets of hope theory, including a description of hope as a cognitive construct related to goal pursuit, an illustration of agency and pathways thinking, and a discussion of barriers and the negative emotions they can elicit. Second, the therapist helps the client identify meaningful goals. Goal identification can be accomplished by encouraging the client to reflect on his or her satisfaction in various "life domains" such as school, work, and relationships. After the client identifies a personally-relevant goal, the therapist and client generate multiple pathways toward its accomplishment. Pathways cognitions can be increased by breaking goals into more manageable parts, 
anticipating obstacles, and planning alternative routes in case of setbacks. Finally, the therapist targets clients' agentic cognitions, typically through the use of narratives or personal story-telling. For example, the therapist might encourage clients to relate and transcribe stories about events in their childhood that illustrate their capacity to face psychosocial challenges. The therapist might teach clients to identify low-hope elements of these narratives and replace them with positive, hopeful thoughts. Alternatively, with younger clients, the therapist might read stories about individuals who exemplify hope. Specific strategies for eliciting hope have been extensively described in The Psychology of Hope (Snyder, 1994), Hope for the Journey (Snyder, McDermott, Cook, \& Rapoff, 1997), Making Hope Happen (McDermott \& Snyder, 1999), The Great Big Book of Hope (McDermott \& Snyder, 2000) and The Handbook of Hope (Snyder, 2000).

Whereas Snyder's hope theory has shaped the field of positive psychology, Herth's 2000;2001) conceptualization of hope has greatly influenced the fields of health psychology, nursing, and medicine. Like Snyder, Herth views hope as "a motivational and cognitive attribute that is theoretically necessary to initiate and sustain action toward goal attainment" (Arnau, Martinez, Guzman, Herth, \& Konishi, 2010, p. 808). Unlike Snyder, however, Herth is primarily concerned with people's future goals as they relate to coping with medical illness, interpersonal loss, or other psychophysical stressors. Based on several cross-sectional and longitudinal studies of cancer patients, adults with terminal illness, and older adults living in nursing homes, Herth identified three dimensions of hope that correlate with patients' psychosocial functioning.

Herth's "cognitive-temporal" dimension of hope is conceptually similar to Snyder's notion of agency thinking; it refers to individuals' beliefs that they can realistically attain desired objectives or outcomes (Arnau et al., 2010). For example, a woman recently diagnosed with breast cancer might view "an immediate return to 'normal' life" as an implausible goal; but instead, view "coping with my illness as best as I can" as more realistic (Kylma, Duggleby, Cooper, \& Molander, 2009). Herth's second, "affective-behavioral" dimension of hope is theoretically similar to Snyder's pathways component; it reflects people's confidence that their plans or actions will lead to goal attainment (Arnau et al., 2010). For example, to cope with her illness, a woman with cancer might reduce her hours at work, seek assistance with household chores, and ask a friend for help with childcare. Herth's third dimension of hope has no corresponding component in Snyder's model. This "affiliative-contextual" dimension refers to people's perceived social support, spiritual support, and sense of belongingness. For example, a woman with cancer might rely more on family and friends, join a support group, or devote time to meditation or prayer. Factor-analytic studies, involving healthy adults, older adults, persons coping with medical illness, and individuals grieving the loss of loved ones support Herth's dimensional model.

Herth's model has also been used to guide interventions in nursing and medicine (Kylma et al., 2009; Schrank, Stanghellini, \& Slade, 2008). The Hope Intervention Program (Herth, 2001) draws heavily on Herth's model to improve the coping strategies and quality of life of individuals with cancer and other serious illnesses. The program is administered in small groups, facilitated by trained mental health or nurse practitioners. Components of the program target the theoretical dimensions of hope. For example, participants are taught to set personally-meaningful and plausible goals, to 
break these goals into manageable steps, and to flexibly modify these steps in the face of setbacks or obstacles. Furthermore, like Snyder's hope enhancement strategies, participants are encouraged to share stories about challenges in their own lives (or in the lives of family members or friends) and to explore how these challenges show courage and optimism. Finally, considerable time is spent fostering a sense of community within the group, encouraging participants to draw upon others for support outside the group, and helping participants find meaning in their illness or loss.

\section{Hope-Enhancement in the Clinic and Community}

Several authors advocate the use of hope enhancement strategies in clinical settings and in the community. For example, Snyder, Lopez, and Pedrotti (2011) describe "hope therapy, " a series of interventions designed to elicit hopeful cognitions and reduce distress among adults referred to individual, marital, and group counseling. Similarly, Magyar-Moe (2010) views hope as "a malleable strength that can serve as an important therapeutic change agent" (p. 141). She describes several hope enhancement strategies and suggests that mental health practitioners use these techniques in their practice. Cheavens and colleagues offer specific ways therapists might increase hopeful thoughts in their clients within the context of cognitive therapy (Cheavens, Feldman et al., 2006) and describe how clinicians might use various hope enhancement strategies to treat patients with Major Depressive Disorder (Cheavens \& Gum, 2010). Others suggest using hope enhancement techniques with children. For example, Nel (2010) describes how clinicians might use narrative approaches to instill hope in clinic-referred youths Snyder, McDermott, and colleagues (1997). describe how similar hope enhancement strategies can be used to treatment Attention-Deficit/Hyperactivity Disorder, Major Depressive Disorder, and Oppositional Defiant Disorder in children. Furthermore, Lopez and colleagues (2009) describe how these strategies might be implemented in public schools "for enhancing hope in all children" (p. 42). Hope enhancement strategies have also been suggested in related disciplines, such as counseling (Larsen \& Stege, 2010), marriage and family therapy (Ripley \& Worthington, 2002), health psychology (Hollis, Massey, \& Jevne, 2007), and nursing (Herth, 2001; Turner \& Stokes, 2006).

Although these interventions are based on thoughtful and well-researched models of hope, and they have become popular in recent years, their effectiveness has not been adequately examined (Kirschman, Johnson, Bender, \& Roberts, 2009). Before these strategies are recommended as a way to reduce psychological distress, cope with illness or loss, or improve the lives of adults and children, it is necessary to demonstrate that hope is, indeed, a malleable construct, that hope enhancement strategies can increase hopeful cognitions, and that these strategies are associated with symptom reduction or improvement in subjective well-being. Without such evidence, it may be premature to recommend these hope enhancement strategies for clinic-referred individuals, persons coping with medical illness or interpersonal loss, or members of the general community.

In this study, we used meta-analysis to obtain an initial quantitative estimate of the effectiveness of hope enhancement strategies in increasing hope, reducing distress, and improving the quality of life for clinic-referred and community-based individuals. At the very least, hope enhancement strategies should be associated with increased 
hopefulness in individuals who participate in them. Furthermore, the utility of hope enhancement strategies for these individuals would be supported by significant effect sizes that are comparable in magnitude to traditional interventions designed to alleviate distress in clinic-referred individuals (e.g., cognitive-behavior therapy for depression), or already-existing positive psychological interventions designed to increase wellbeing (e.g., optimism, self-efficacy, self-esteem, social problem-solving). Such evidence would support the recommendations of previous authors who advocate the use of hope enhancement strategies in the clinic and community.

\section{Method}

\section{Study Selection}

To be included in the meta-analysis, each study must have met the following criteria: the study (a) examined the effectiveness of a psychosocial intervention designed to increase hope in children, adolescents, or adults, (b) measured hope quantitatively, using a valid self-report rating scale, (c) employed hope-enhancing techniques outlined in one of the treatment manuals listed above or based on hope theory, (d) published in English, and (e) contained sufficient information to compute an effect size.

Manuscripts published between 1994 and 2011 were identified through relevant computerized bibliographic databases (i.e., Academic Search Complete, ERIC, Medline, PsycInfo). In order to reduce availability and source bias in study selection, we also searched the Dissertation Abstracts database for relevant studies (Hunter \& Schmidt, 2004). To avoid a high rate of false rejections, we used the following broad search terms: hope, hope theory, hope therapy, hope enhancement, hopefulness, hopelessness, and positive psychological interventions. Finally, we located studies through published review articles and references in previously-identified manuscripts. This strategy identified 179 studies that were screened based on the inclusionary criteria, leaving 27 studies for analysis. Most of the studies that were excluded from our analysis were theoretical in nature and did not involve the empirical investigation of hope. Many of the remaining, empirical studies excluded from our analysis examined correlations between hope and other psychosocial variables (e.g., depression, optimism, self-efficacy) and did not involve the manipulation of participants' hopefulness.

\section{Dependent Measures}

The studies included in the analysis used a variety of measures to assess the outcomes of the hope enhancement strategies. We organized these dependent measures into three broad classes: (a) hope, (b) psychological distress, and (c) life satisfaction.

Hope

Most studies ( $k=19$; number of studies) used either the Hope Scale (Snyder et al., 1991; 1996) or Children's Hope Scale (Snyder, Hoza et al., 1997), to assess their intervention's ability to enhance hope in participants. Other studies $(k=7)$ relied on the Herth Hope Scale (Herth, 2000) ${ }^{1}$. Both self-report instruments yield an overall score that reflects state hopefulness. The psychometric properties of these instruments indicate adequate internal consistency, content validity, and convergence with theoretically-similar constructs, such as optimism and self-efficacy. 


\section{Psychological Distress}

Several studies $(k=9)$ examined the effects of the hope-enhancement intervention on participants' psychological distress. Distress was measured using a variety of self-report questionnaires including the Beck Depression Inventory (Beck, Steer, \& Brown, 1996), the Center for Epidemiologic Studies Depression Scale (Radloff, 1977), the State-Trait Anxiety Inventory (Spielberger, 1983) and the negative affect dimension of the Positive and Negative Affect Scales (Tellegen, Watson, \& Clark, 1999).

${ }^{1}$ One hope intervention study (Ripley \& Worthington, 2002) did not report a hope outcome measure; consequently, $k=26$ for our analysis of hope outcomes.

\section{Life Satisfaction}

Several studies $(k=10)$ also assessed the effects of the hope-enhancement strategy on participants' self-reported life satisfaction or subjective well-being. Measures included the Multidimensional Students' Life Satisfaction Scale (Huebner, Laughlin, Ash, \& Gilman, 1998), the Self-Esteem Scale (Rosenberg, 1989), the Satisfaction with Life Scale (Diener, Emmons, Larsen, \& Griffin, 1985), and the positive affect dimension of the Positive and Negative Affect Scales (Tellegen et al., 1999).

\section{Moderator (Independent) Variables}

We coded nine characteristics of each study that we believed might influence the outcomes of the analyses. Two characteristics concerned each study's design. First, we determined whether each study used an experimental $(k=12)$ or quasi-experimental $(k=15)$ design. Experimental studies were defined by the practice of randomly assigning participants to a hope-enhancement condition or to a comparison group that did not receive a hope-enhancing intervention. We reasoned that studies relying on experimental designs might have greater methodological rigor. Second, we coded each study based on whether outcomes were assessed using one of the Snyder Hope Scales $(k=20)$ or the Herth Hope Index $(k=7)$. We wanted to make sure that results were not dependent on the outcome measured used.

Two additional characteristics concerned each study's participants. First, we categorized studies based on the age of participants: children and adolescents $(k=6)$ or adults $(k=21)$. We suspected that intervention outcomes might vary as a function of age, perhaps because of differences in cognitive and socioemotional maturity across development. Second, we classified studies based on the population from which participants were recruited. Most studies $(k=17)$ included participants recruited from psychiatric clinics, hospitals, or other at-risk settings (e.g., youths in residential treatment, support groups for survivors of incest). Other studies $(k=10)$ included participants recruited from schools, colleges, or the community (e.g., introductory psychology students, community members recruited through newspaper advertisements).

Four characteristics concerned the nature of the hope enhancement strategy used in each study. First, we classified studies based on whether the hope intervention was administered in individual $(k=10)$ or group $(k=17)$ format. Second, we coded studies based on whether the intervention followed a treatment manual or written protocol $(k$ $=23$ ) or whether no such manual or protocol was mentioned in the manuscript ( $k=$ 4). Third, we divided studies based on the context of the intervention. Most of the interventions $(k=21)$ were administered by mental health professionals, medical professionals, or clinical trainees (e.g., postdoctoral students) in a clinic, hospital, or other applied human service setting. Several studies $(k=6)$ were conducted by researchers 
or research assistants in the context of a research setting (i.e., university laboratory). Fourth, we coded each study based on whether the intervention involved one session $(k=7)$ or multiple sessions $(k=20)$.

Finally, we categorized studies based on whether they were published $(k=21)$ or were unpublished dissertations $(k=6)$. We wanted to rule out the possibility of publication bias in our results (Rosenthal, 1979).

Each study was independently coded by the first and second authors. Cohen's kappa exceeded .90 for all categorical variables. Disagreements were resolved through review of each study and discussion.

\section{Effect Size Calculation}

Following the recommendations of Lipsey and Wilson (2001), Cohen's $d$ was calculated as the measure of effect size for all analyses. For between-group analyses, Cohen's $d$ reflects the difference between the means of the hope intervention and control groups after treatment, divided by the pooled standard deviation of the sample, and controlling for sample size (i.e., the standard mean difference). For studies without control groups, Cohen's $d$ reflects the difference between pre- and post-treatment means divided by the pooled standard deviation (i.e., the standardized mean gain; Cohen 1988). In most cases, Cohen's $d$ was calculated directly from means and standard deviations reported in the articles; in some cases, Cohen's $d$ was estimated using other statistics (e.g., results of $t$ tests). If descriptive statistics were not provided, and the article reported nonsignificant findings, an effect size of zero was used (Lipsey \& Wilson, 2001). In all cases, positive $d$ statistics indicate superior functioning in the intervention group compared to the control group or superior functioning posttreatment compared to pretreatment (e.g., higher hope and life satisfaction, or lower psychological distress associated with the intervention).

Mean effect sizes were calculated according to the procedures outlined by Lipsey and Wilson (2001). Three data files were created, one for each of the three categories of dependent variables: (a) hope, (b) psychological distress, and (c) life satisfaction. Some studies assessed two dependent variables within the same category (e.g., both depression and anxiety were assessed). In this case, the average effect size for the two measures was used to reflect the study's outcome, so that each study provided only one effect size for each of the dependent variable categories (Lipsey \& Wilson, 2001). Each effect size was weighted by the inverse square of its variance (Hedges \& Olkin, 1985). Effect sizes $\leq .30$ are considered small, effect sizes between .31 and .66 are considered moderate, and effect sizes $\geq .67$ are considered large (Lipsey and Wilson, 2001).

In addition to calculating overall effect sizes, we examined the homogeneity of study outcomes using the within-class goodness-of-fit statistic (Qw). A significant Qw indicates heterogeneity within a group of studies and suggests that another variable might moderate the relationship between the intervention and the studies' outcomes. Possible moderators were tested using the between-class goodness-of-fit statistic $(\mathrm{Qb})$. A significant $\mathrm{Qb}$ indicates a significant difference in the magnitude of the effect sizes between categories of the moderator variable.

\section{Results}

Table 1 presents a description of the individual studies and their corrected effect sizes on each of the three dependent variable categories (i.e., hope, psychological distress, 
Table 1 Study Characteristics and Effect Sizes

\begin{tabular}{|c|c|c|c|c|c|c|}
\hline \multirow[b]{3}{*}{ Author(s) } & \multirow[b]{3}{*}{$\mathbf{N}$} & \multirow[b]{3}{*}{ Moderators } & \multirow[b]{3}{*}{ Intervention/Sample } & \multicolumn{3}{|c|}{ Effect Sizes } \\
\hline & & & & & Psychological & Life \\
\hline & & & & Hope & Distress & Satisfaction \\
\hline $\begin{array}{l}\text { Berg et al. } \\
\text { (2008) }\end{array}$ & 172 & $\begin{array}{l}1 / 1 / 2 / 3 / 1 / 1 / \\
2 / 1 / 1\end{array}$ & $\begin{array}{l}\text { Hope intervention/guided imagery } \\
\text { for college students }\end{array}$ & .42 & & \\
\hline $\begin{array}{l}\text { Bouwkamp } \\
\text { (2001) }\end{array}$ & 30 & $\begin{array}{l}2 / 1 / 1 / 3 / 2 / 1 / \\
1 / 2 / 2\end{array}$ & $\begin{array}{l}\text { Making Hope Happen program for } \\
\text { high school students }\end{array}$ & .10 & & \\
\hline $\begin{array}{l}\text { Buchanan } \\
\text { (2007) }\end{array}$ & 20 & $\begin{array}{l}1 / 1 / 1 / 1 / 2 / 1 / \\
1 / 2 / 2\end{array}$ & $\begin{array}{l}\text { Making Hope Happen program for } \\
\text { youths in special education }\end{array}$ & -.64 & & -.14 \\
\hline Buckland (2010) & 12 & $\begin{array}{l}2 / 2 / 2 / 1 / 1 / 1 / \\
1 / 2 / 2\end{array}$ & $\begin{array}{l}\text { Hope-based intervention for adults } \\
\text { with schizophrenia }\end{array}$ & .40 & & \\
\hline $\begin{array}{l}\text { Cheavens et al. } \\
\text { (2006) }\end{array}$ & 32 & $\begin{array}{l}1 / 1 / 2 / 3 / 2 / 1 / \\
1 / 2 / 1\end{array}$ & $\begin{array}{l}\text { Hope enhancement group for } \\
\text { adults from the community }\end{array}$ & .34 & .42 & .01 \\
\hline $\begin{array}{l}\text { Coppock et al. } \\
\text { (2010)a }\end{array}$ & 43 & $\begin{array}{l}2 / 1 / 2 / 1 / 1 / 2 / \\
1 / 2 / 1\end{array}$ & $\begin{array}{l}\text { Hope-based therapy for adult } \\
\text { psychiatric outpatients }\end{array}$ & .11 & & \\
\hline $\begin{array}{l}\text { Curry \& Snyder } \\
(2000)\end{array}$ & 186 & $\begin{array}{l}2 / 1 / 2 / 3 / 2 / 1 / \\
2 / 2 / 1\end{array}$ & $\begin{array}{l}\text { Hope enhancement intervention } \\
\text { for college students }\end{array}$ & .38 & & .21 \\
\hline $\begin{array}{l}\text { Duggleby et al. } \\
\text { (2007) }\end{array}$ & 58 & $\begin{array}{l}1 / 2 / 2 / 2 / 1 / 1 / \\
1 / 1 / 1\end{array}$ & $\begin{array}{l}\text { Living with Hope Program for } \\
\text { adults with terminal cancer }\end{array}$ & .43 & & .43 \\
\hline Herth (2000)a & 75 & $\begin{array}{l}2 / 2 / 2 / 2 / 2 / 1 / \\
1 / 2 / 1\end{array}$ & $\begin{array}{l}\text { Hope Intervention Program for } \\
\text { adults with recurrent cancer }\end{array}$ & .38 & .23 & \\
\hline $\begin{array}{l}\text { Irving et al. } \\
(2004)\end{array}$ & 98 & $\begin{array}{l}1 / 1 / 2 / 1 / 2 / 1 / \\
1 / 2 / 1\end{array}$ & $\begin{array}{l}\text { Hope-based group therapy for } \\
\text { adult psychiatric outpatients }\end{array}$ & .00 & .00 & .00 \\
\hline $\begin{array}{l}\text { Kirschman et al. } \\
\text { (2010) }\end{array}$ & 391 & $\begin{array}{l}2 / 1 / 1 / 1 / 2 / 2 / \\
1 / 2 / 1\end{array}$ & $\begin{array}{l}\text { Hope-based summer camp for at- } \\
\text { risk youth }\end{array}$ & .20 & & \\
\hline $\begin{array}{l}\text { Klausner et al. } \\
\text { (1998) }\end{array}$ & 13 & $\begin{array}{l}1 / 1 / 2 / 1 / 2 / 1 / \\
1 / 2 / 1\end{array}$ & $\begin{array}{l}\text { Goal-focused group therapy for } \\
\text { older adults with depression }\end{array}$ & .38 & .40 & \\
\hline $\begin{array}{l}\text { McDowell } \\
\text { (2009) }\end{array}$ & 7 & $\begin{array}{l}2 / 1 / 2 / 2 / 1 / 1 / \\
1 / 2 / 2\end{array}$ & $\begin{array}{l}\text { Hope intervention/guided imagery } \\
\text { for stroke patients }\end{array}$ & 1.40 & & \\
\hline $\begin{array}{l}\text { McNeal et al. } \\
\text { (2006) }\end{array}$ & 155 & $\begin{array}{l}2 / 1 / 1 / 1 / 2 / 2 / \\
1 / 2 / 1\end{array}$ & $\begin{array}{l}\text { Hope-based group therapy for } \\
\text { youth in residential treatment }\end{array}$ & .31 & & \\
\hline $\begin{array}{l}\text { Nedderman et } \\
\text { al. (2010) }\end{array}$ & 39 & $\begin{array}{l}2 / 2 / 2 / 1 / 2 / 1 / \\
1 / 2 / 1\end{array}$ & $\begin{array}{l}\text { Hope-based group therapy for } \\
\text { incarcerated women }\end{array}$ & .31 & & \\
\hline Pedrotti (2008) & 104 & $\begin{array}{l}2 / 1 / 1 / 3 / 2 / 1 / \\
1 / 2 / 1\end{array}$ & $\begin{array}{l}\text { Making Hope Happen program for } \\
\text { junior high school students }\end{array}$ & .11 & & \\
\hline $\begin{array}{l}\text { Pretorius et al. } \\
\text { (2008) }\end{array}$ & 24 & $\begin{array}{l}2 / 1 / 2 / 3 / 2 / 1 / \\
1 / 2 / 1\end{array}$ & $\begin{array}{l}\text { Hope enhancement group for } \\
\text { adults from the community }\end{array}$ & .94 & -.10 & -.20 \\
\hline $\begin{array}{l}\text { Ripley \& } \\
\text { Worthington } \\
\text { (2002) }\end{array}$ & 43 & $\begin{array}{l}2 / 1 / 2 / 3 / 2 / 1 / \\
1 / 2 / 1\end{array}$ & $\begin{array}{l}\text { Hope-based couples therapy for } \\
\text { adults from the community }\end{array}$ & & & .07 \\
\hline $\begin{array}{l}\text { Robitschek } \\
\text { (1996)b }\end{array}$ & 98 & $\begin{array}{l}2 / 1 / 1 / 1 / 2 / 2 / \\
2 / 1 / 1\end{array}$ & $\begin{array}{l}\text { Hope enhancement program for at- } \\
\text { risk youths }\end{array}$ & .44 & & \\
\hline $\begin{array}{l}\text { Rustoen et al. } \\
\text { (1998)c }\end{array}$ & 96 & $\begin{array}{l}1 / 2 / 2 / 2 / 2 / 1 / \\
1 / 2 / 1\end{array}$ & $\begin{array}{l}\text { Hope intervention program for } \\
\text { adults with cancer }\end{array}$ & .35 & & .10 \\
\hline $\begin{array}{l}\text { Rustoen et al. } \\
(2010) c\end{array}$ & 194 & $\begin{array}{l}2 / 2 / 2 / 2 / 2 / 1 / \\
1 / 2 / 1\end{array}$ & $\begin{array}{l}\text { Hope intervention program for } \\
\text { women with breast cancer }\end{array}$ & .08 & & \\
\hline $\begin{array}{l}\text { Snyder et al. } \\
\text { (1996a)d }\end{array}$ & 60 & $\begin{array}{l}1 / 1 / 2 / 3 / 1 / 1 / \\
2 / 1 / 1\end{array}$ & $\begin{array}{l}\text { Goal pursuit task involving college } \\
\text { students }\end{array}$ & .14 & & \\
\hline $\begin{array}{l}\text { Snyder et al. } \\
\text { (1996b)d }\end{array}$ & 60 & $\begin{array}{l}1 / 1 / 2 / 3 / 1 / 1 / \\
2 / 1 / 1\end{array}$ & $\begin{array}{l}\text { Recall of successful goal pursuit } \\
\text { involving college students }\end{array}$ & .31 & & \\
\hline Trump (1997) & 42 & $\begin{array}{l}1 / 1 / 2 / 1 / 2 / 1 / \\
1 / 1 / 2\end{array}$ & $\begin{array}{l}\text { Hopeful narratives for adult } \\
\text { survivors of incest }\end{array}$ & .34 & -.06 & .34 \\
\hline Vlach (2006) & 27 & $\begin{array}{l}2 / 1 / 2 / 1 / 1 / 1 / \\
1 / 2 / 2\end{array}$ & $\begin{array}{l}\text { Hope-based journaling intervention } \\
\text { for psychiatric outpatients }\end{array}$ & -.05 & -.15 & \\
\hline $\begin{array}{l}\text { Wilson et al. } \\
(2010)\end{array}$ & 15 & $\begin{array}{l}1 / 2 / 2 / 1 / 1 / 1 / \\
1 / 2 / 1\end{array}$ & $\begin{array}{l}\text { Hope-based intervention for } \\
\text { depressed nursing home residents }\end{array}$ & -.10 & -.02 & \\
\hline Ziv et al. (2011) & 60 & $\begin{array}{l}1 / 1 / 2 / 3 / 1 / 1 / \\
2 / 1 / 1\end{array}$ & $\begin{array}{l}\text { Exposure to positive music for } \\
\text { college students }\end{array}$ & .53 & .27 & .07 \\
\hline
\end{tabular}

Effect sizes are reported as Cohen's $d$. For standardized mean differences, Cohen's $d$ has been corrected to control for sample size bias. Moderator codes are as follows: (a) research design, 1 = experimental, 2 = quasi-experimental; (b) 
outcome measure, 1 = Snyder Hope Scale, 2 = Herth Hope Scale; (c) age of participants, 1 = child/adolescent, 2 = adult; (d) recruitment of participants, 1 = psychiatric or medical facility, 2 = school, university, or community; (e) delivery of intervention, 1 = individual, 2 = group; (f) manualized intervention, $1=$ manual $/$ protocol, $2=$ no manual $/$ protocol; $(\mathrm{g})$ context of intervention, $1=$ mental health or medical professional in clinic/hospital, $2=$ researcher or research assistant in research setting; (h) dose of intervention, 1 = single session, 2 = multiple sessions; (i) publication status, $1=$ published, 2 = unpublished dissertation.

a Examined changes in hope from first to last session.

b Outcomes assessed immediately after the intervention.

c Mean effect size for agency and pathways scores reported separately in the manuscript.

d Hope-enhancement group compared to no-treatment control group.

life satisfaction). Table 2 displays mean effect sizes, confidence intervals, and homogeneity tests for hope, psychological distress, and life satisfaction, respectively. As can be seen from Table 2, the mean effect size for hope was .22, suggesting that hope enhancement strategies are associated with significant increases in self-reported hopefulness among participants, $z(25)=8.87, p<.001$. The $95 \%$ confidence interval indicates that the effect falls entirely within the "small" range using Lipsey and Wilson's

Table 2 Mean Effect Sizes, Confidence Intervals, and Tests of Homogeneity for Hope Interventions

\begin{tabular}{|c|c|c|c|c|c|}
\hline Outcome Variable/Moderator & d & k & $\begin{array}{l}\text { Confidence } \\
\text { Interval (95\%) }\end{array}$ & $\mathrm{Q}_{\mathrm{w}}$ & $\mathrm{Q}_{\mathrm{b}}$ \\
\hline Hope & .22 & 26 & $.17 / .27$ & $40.44^{*}$ & \\
\hline \multicolumn{6}{|l|}{ Research Design } \\
\hline Experimental & .28 & 12 & $.13 / .43$ & 8.84 & \\
\hline Quasi-experimental & .21 & 14 & $.16 / .26$ & $30.92^{*}$ & .68 \\
\hline \multicolumn{6}{|l|}{ Outcome Measure } \\
\hline Snyder Hope Scale & .23 & 19 & $.18 / .28$ & $34.32^{*}$ & \\
\hline Herth Hope Scale & .15 & 7 & $.03 / .27$ & 4.81 & 1.31 \\
\hline \multicolumn{6}{|l|}{ Age of Participants } \\
\hline Children/adolescents & .24 & 6 & $.17 / .31$ & 10.77 & \\
\hline Adults & .20 & 20 & $.13 / .27$ & 28.90 & .77 \\
\hline \multicolumn{6}{|l|}{ Recruitment of Participants } \\
\hline Psychiatric/medical facility & .19 & 17 & $.14 / .25$ & $29.77^{*}$ & \\
\hline School/community & .30 & 9 & $.19 / .41$ & 8.06 & $2.61 \dagger$ \\
\hline \multicolumn{6}{|l|}{ Delivery of Intervention } \\
\hline Individual & .17 & 10 & $.07 / .27$ & $17.08^{*}$ & \\
\hline Group & .23 & 16 & $.18 / .29$ & 22.29 & 1.08 \\
\hline \multicolumn{6}{|l|}{ Intervention Manual } \\
\hline Manual/protocol used & .20 & 22 & $.13 / .28$ & 31.44 & \\
\hline No manual/protocol used & .23 & 4 & $.17 / .29$ & $8.71^{*}$ & .29 \\
\hline \multicolumn{6}{|l|}{ Context of Intervention } \\
\hline Clinical/medical setting & .18 & 20 & $.13 / .23$ & 27.34 & \\
\hline Research setting & .39 & 6 & $.28 / .51$ & 1.51 & $11.59^{*}$ \\
\hline \multicolumn{6}{|l|}{ Dose of Intervention } \\
\hline One session & .40 & 7 & $.26 / .54$ & 1.52 & \\
\hline Multiple sessions & .19 & 19 & $.14 / .25$ & $31.24^{*}$ & $7.68^{*}$ \\
\hline \multicolumn{6}{|l|}{ Publication Status } \\
\hline Published study & .23 & 20 & $.18 / .28$ & 24.36 & \\
\hline Unpublished dissertation & .09 & 6 & $-.06 / .24$ & $12.88^{*}$ & $3.20+$ \\
\hline Psychological distress & .04 & 9 & $-.12 / .19$ & 4.85 & \\
\hline Life satisfaction & .16 & 10 & $.03 / .28$ & 6.22 & \\
\hline
\end{tabular}

Effect sizes are reported as Cohen's $d$. Mean effect sizes are weighted by the inverse variance to control for biases in precision (Lipsey \& Wilson, 2001). $\mathrm{k}=$ number of studies; $\mathrm{Q}=$ goodness of fit statistic (test of homogeneity); ${ }^{*} p \leq .05$. $\dagger$ $p \leq .10$. 
(2001) criteria. Furthermore, the within-groups goodness-of-fit statistic indicates significant heterogeneity of outcomes.

Results of moderator analyses, also shown in Table 2, yielded two significant differences and one borderline-significant difference in outcomes as a function of the type of hope enhancement strategy. First, interventions that were administered by researchers or research assistants in the context of a laboratory-based research setting yielded significantly larger effect sizes $(d=.39)$ than interventions administered by mental health or medical professionals in the context of a clinic or hospital setting $(d=.18)$, $\mathrm{Qb}(1)=11.59, p<.001$. Second, interventions that lasted only one session yielded significantly larger effect sizes $(d=.40)$ than interventions that were administered over multiple sessions $(d=.19), \mathrm{Qb}(1)=7.68, p=.006$. Finally, interventions that involved participants recruited from schools, universities, and the general community yielded marginally larger effects sizes $(d=.30)$ than interventions that involved psychiatricallyor medically-referred individuals ${ }^{1}(d=.19), \mathrm{Qb}(1)=2.61, p=.09$.

The moderation test for publication status was borderline-significant, with published studies yielding marginally larger effect sizes $(d=.23)$ than unpublished dissertations $(d=.09), \mathrm{Qb}(1)=3.20, p=.069$. The mean effect size for unpublished studies was not significant, $z(5)=1.16 p=.25$. None of the other potential moderators were associated with hope outcomes.

${ }^{1}$ The effect sizes for studies involving psychiatrically-referred samples $(k=12, d=$ .21) and medically-referred samples $(k=5, d=.16)$ did not differ significantly, $\mathrm{Qb}(1)=$ $.395, p=.529$.

Table 2 also shows that the mean weighted effect sizes for the relationship between hope enhancement strategies and participants' self-reported psychological distress and life satisfaction. The mean effect size for psychological distress was not significant: $z(8)$ $=.448, p=.65, d=.04$. In contrast, the mean effect size for life satisfaction was significant, $z(9)=2.42, p=.016, d=.16$, although the 95\% confidence interval fell entirely within the "small" range according to Lipsey and Wilson's (2001) criteria. Goodnessof-fit statistics indicated homogeneity within studies for both the distress and satisfaction variables, indicating no need for moderation tests (Lipsey \& Wilson, 2001).

\section{Discussion}

The last two decades have seen marked developments in our understanding of hope. C. R. Snyder's (1994) hope theory enjoys considerable theoretical and empirical support as an explanatory model for hope. Similarly, Herth's (2000) conceptualization of hopefulness has greatly influenced the practice of health psychology, nursing, and medicine. However, the current study provides only modest evidence for the ability of hope enhancement strategies based on these models to increase hopefulness or improve life satisfaction among participants and no consistent evidence that hope enhancement strategies can alleviate psychological distress.

The mean effect of hope enhancement strategies in increasing self-reported hopefulness was significant, but small $(d=.22)$. Normative data from more than 300 metaanalyses of psychosocial and psychoeducational interventions indicate that only about $25 \%$ of studies yield effect sizes in the "small" range, as seen in our analysis (Lipsey \& Wilson, 1993). The fact that hope enhancement strategies are only weakly associated with increased hopefulness calls into question the mechanism by which these strategies 
are believed to improve participants' functioning or increase their satisfaction with life. It is possible that hope may not be as malleable as some theorists have suggested, that the strategies recommended by hope therapy advocates (e.g., goal-setting, story-telling) are not especially effective at increasing hopefulness, or that the intensity of these interventions has been insufficient in previous studies. Given the fact that hope is associated with a wide range of psychosocial and physical benefits (Snyder et al., 2011), and appears to be an important component of therapeutic change (Snyder \& Lopez, 2009) and coping with adversity (Linley \& Joseph, 2004), it is disappointing that strategies designed to target and systematically increase hope yield such small overall effects.

Just as disappointing was our finding that these hope enhancement strategies are only weakly associated with improvements in participants' life satisfaction. The mean effect size for increased life satisfaction was small $(d=.16)$. In comparison, a recentmeta-analysis showed that more traditional, behaviorally-based psychosocial interventions are associated with much larger increases in life satisfaction or subjective wellbeing (mean $d=.52$; Mazzucchelli, Kane, \& Rees, 2010). Furthermore, other positive psychological interventions are associated with moderate to large increases in wellbeing (mean $d=.61$; Sin \& Lyubomirsky, 2009). Indeed, several randomized controlled studies have demonstrated the efficacy of strategies to systematically increase other positive psychological constructs such as gratitude, optimism, forgiveness, and mindfulness in order to increase happiness (Sin, Della Porta, \& Lyubomirsky, 2011). Furthermore, positive psychologists have begun to incorporate these strategies into their work with clinic-referred individuals (Layous, Chancellor, Lyubomirsky, Wang, \& Doraiswamy, in press). Our findings suggest that these positive psychological interventions would likely have a greater impact on individuals in the community and the clinic than hope enhancement strategies per se.

Finally, hope enhancement strategies were not associated with overall reductions in depression, anxiety, or psychological distress $(d=.04)$. In comparison, meta-analyses indicate that traditional psychotherapy is associated with moderate to large reductions in psychological symptoms (mean $d=.75$; Lambert \& Ogles, 2004). Furthermore, other positive psychological interventions yield moderate to large effect sizes with respect to their ability to reduce depression (mean $d=.64$; Sin \& Lyubomirsky, 2009). Altogether, these findings call into question the merits of hope enhancement for individuals experiencing psychological or medical problems and indicate that hope "therapies" should not be considered first-line interventions for clinically- or medically-referred individuals.

Our moderation analyses revealed two significant differences and one borderline-significant difference in the magnitude of effect sizes across categorical variables. Collectively, these differences call into question the utility of hope enhancement strategies in applied settings with clinic-referred or at-risk populations.

First, interventions that were administered by researchers in the context of a university research study yielded significantly larger effect sizes $(d=.39)$ than interventions administered by mental health or medical professionals in the context of a clinic or hospital $(d=.18)$. This finding is noteworthy, because it suggests that hope is, indeed, a malleable construct under carefully controlled, laboratory conditions. Such malleability has been used to validate both the Snyder Hope Scale (Snyder et al., 1991; Snyder et al., 1996) and Herth Hope Index Herth 2000; 2001, and to demonstrate the value of 
hope as a social psychological construct related to optimal functioning. However, our results call into question the effectiveness of hope enhancement strategies in applied settings. Whereas researchers can demonstrate hope enhancement using laboratorybased procedures under optimal conditions (e.g., asking college students to engage in a guided imagery exercise or to listen to pleasant music in a lab), clinicians seem to have difficulty increasing hope in patients experiencing psychological distress or coping with illness. This difference may reflect a larger problem in clinical research, namely, the challenge of demonstrating that interventions are both efficacious when administered under optimal conditions and effective when applied to real-world contexts (Lambert \& Ogles, 2004; Vernig, 2007). Hope-enhancement strategies should demonstrate effectiveness in human-service settings before they can be recommended for use in clinics and hospitals.

Second, interventions lasting only one session yielded significantly larger effect sizes $(d=.40)$ than interventions conducted over multiple sessions $(d=.19)$. At first blush, this finding seems counterintuitive; we would likely expect longer interventions to yield more marked results. However, closer inspection shows that most (71\%) interventions that lasted only one session were conducted in research settings whereas most (95\%) interventions conducted over multiple sessions were conducted in applied settings. The significant difference in effect sizes across brief and sustained interventions may be an artifact of this difference in setting. Interventions administered over multiple sessions may have yielded smaller effects because they tended to be directed toward individuals in clinics, hospitals, and other human-service settings.

Third, studies that relied on participants from schools, colleges, or the community yielded marginally larger effect sizes $(d=30)$ than studies that recruited psychiatric patients, medical patients, or other at-risk individuals (e.g., youths in residential treatment; $d=19$ ). This finding stands in contrast to previous assertions that individuals with the lowest levels of hope benefit the most from hope enhancement strategies (Lopez, et al. 2009). Rather, it appears that individuals experiencing greater risk, and likely less hope, may not be able to take advantage of these hope enhancement strategies compared to their higher-functioning counterparts in college or the community.

Finally, we observed a borderline-significant difference in the magnitude of effect sizes generated by published studies $(d=.23)$ compared to unpublished dissertations $(d=.09)$. Indeed, the mean effect size for unpublished studies was not significant. This finding is important, because it suggests publication bias. It is also noteworthy because unpublished studies are sometimes used to support the effectiveness of hope enhancement strategies (see Lopez et al., 2004; Pedrotti et al., 2008; Rand \& Cheavens, 2009; Snyder et al., 2011). The effects of hope enhancement strategies were independent of all other moderator variables including research design (i.e., experimental or quasiexperimental), outcome measure (i.e., Snyder or Herth), age of participants (i.e., youths or adults), delivery of intervention (i.e., individual or group), and inclusion of a manual or research protocol.

Our meta-analysis is limited by the relatively small number of studies that have empirically investigated the efficacy or effectiveness of hope enhancement strategies. Although strategies designed to systematically increase hopefulness have been suggested for the past two decades, most manuscripts have been theoretical in nature or have relied on correlational data, case studies, or anecdotal evidence to support their 
use. Consequently, our analysis relies on a relatively small number of studies, especially our calculation of effect sizes for psychological distress and life satisfaction outcomes. The small number indicates that we must interpret effect sizes with caution. On the other hand, our confidence intervals for hope, distress, and satisfaction all fell within the "small" to "non-significant" range, providing very limited evidence for the ability of these strategies to produce desired outcomes. We believe that the small number of empirical, intervention studies, combined with their modest to non-significant results, should prompt clinicians to reconsider using these strategies in their practice and motivate researchers to provide additional evidence demonstrating their utility, especially in applied settings.

Our investigation is also limited by the heterogeneity of studies that we included in our analysis. For example, we included studies conducted across a variety of settings (e.g., clinic, hospital, research), using different outcome measures (e.g., Snyder Hope Scales, Herth Hope Index), and administered to different groups of individuals (e.g., psychological, medical, community-based). This heterogeneity might also reduce the confidence we have in overall statements regarding the merits of hope enhancement strategies. However, we believe that our moderation analyses provide some indication of the conditions under which these strategies demonstrate the greatest utility and show areas where more research is needed before hope enhancement strategies can be widely recommended.

The hope theories developed by Snyder (2000) and Herth (2001) have offered us a useful way of conceptualizing hope as a cognitive construct related to a wide range of social, emotional, and physical benefits. Indeed, these theories have influenced research over the past two decades, demonstrating associations between self-reported hopefulness and academic achievement, athletic performance, physical health and wellness, coping with illness and loss, psychological adjustment, social-emotional problem-solving, and the quality of interpersonal relationships (see Rand \& Cheavens, 2009 for a review). What seems to be missing is strong evidence of a causal link between increased hopefulness and these positive outcomes.

It might be time to consider an alternative interpretation of the correlational data, namely, that the association between hope and these psychosocial benefits runs in the opposite direction. Whereas theorists (Herth, 2000; Snyder et al., 2000) have speculated that increased hopefulness produces beneficial outcomes, it is also possible that academic and athletic achievement, physical and emotional competence, and social support and satisfaction breed hopeful cognitions and positive emotions. If hope is a byproduct, rather than a determinant, of goal attainment, it might be increased though traditional psychotherapies and newer positive psychological interventions already available to clinicians and researchers at this time. Indeed, research involving both children (Weis \& Ash, 2009) and adults (Snyder \& Taylor, 2000) demonstrate increased hopefulness as a result of these interventions.

Alternatively, hope theory can be used to select interventions that are most likely to increase agentic or pathways thinking or improve social support. For example, the principles of behavioral activation and motivational interviewing might be effectively used to help clients set clear, objective, and meaningful goals that can serve as the targets for treatment. Similarly, cognitive interventions may be particularly useful in helping clients recognize and challenge negative thoughts that rob them of their 
motivation to work toward their goals. Behavioral activation techniques can provide clients with greater energy to sustain goal pursuit over time. Furthermore, problemsolving and skills training can help individuals marshal social support to cope with stress and adversity. Other positive psychological interventions can be especially useful in increasing well-being and positive affect. Rather than using hope therapy as a firstline treatment, clinicians may wish to use hope theory as a model from which to select evidence-based treatments and to guide their interventions.

\section{Acknowledgements}

This research was supported by the Laurie Bukovac Hodgson and David Hodgson Endowed Fund.

\section{Author details}

'Department of Psychology, Granville, Ohio, 43023, USA ²Denison University, Granville, Ohio, 43023, USA

\section{Authors' contributions}

RW designed the study, reviewed papers for inclusion in the meta-analysis, and performed the effect size calculations and moderation tests. ECS helped review papers for inclusion in the meta-analysis, coded studies for the moderation tests, and reviewed the manuscript.

\section{Competing interests}

The authors declare that they have no competing interests.

Received: 17 June 2011 Accepted: 8 November 2011 Published: 8 November 2011

References

Arnau RC, Martinez P, Guzman IN, Herth K, Konishi CY: A Spanish-language version of the Hearth Hope Scale: Development and psychometric evaluation. Educational and Psychological Measurement 2010, 70:808-824. Beck AT, Steer RA, Brown GK: Manual for Beck Depression Inventory // San Antonio, TX: Psychological Corporation; 1996. Berg CJ, Snyder CR, Hamilton N: The effectiveness of a hope intervention in coping with cold pressure pain. Journal of Health Psychology 2008, 13:804-809.

Bouwkamp JC: The effects of a hope enhancement program on urban adolescents Unpublished master's thesis, University of Kansas, Lawrence, KS; 2001.

Buchanan CL: Making hope happen for students receiving special education services (Dissertation). Available from ProQuest Dissertations and Theses database 2007, (UMI No. 3303999).

Buckland HT: Young adults with schizophrenia: Defining happiness, building hope (Dissertation). Available from ProQuest Dissertations and Theses database 2010, (UMI No. 3370467).

Cheavens JS, Feldman DB, Gum A, Michael ST, Snyder CR: Hope therapy in a community sample: A pilot investigation. Social Indicators Research 2006, 77:61-78.

Cheavens JS, Feldman DB, Woodward JT, Snyder CR: Hope in cognitive psychotherapies: On working with client strengths. Journal of Cognitive Psychotherapy 2006, 20:135-145.

Cheavens JS, Gum AM: From here to where you want to be: Building the bridges with hope therapy in a case of major depression. In Happiness, healing, enhancement: Your casebook collection for applying positive psychology in therapy. Edited by: Burns GW. Hoboken, NJ: Wiley; 2010:51-63.

Cohen J: Statistical power analysis for the behavioral sciences Hillsdale, NJ: Erlbaum; 1988.

Coppock TE, Owen JJ, Zagarskas E, Schmidt M: The relationship between therapist and client hope with therapy outcomes. Psychotherapy Research 2010, 20:619-626.

Curry LA, Snyder CR: Hope takes the field: Mind matters in athletic performance. In Handbook of hope. Edited by: Snyder CR. San Diego, CA: Academic Press; 2000:243-259.

Diener E, Emmons RA, Larsen RJ, Griffin S: The Satisfaction with Life Scale. Journal of Personality Assessment 1985, 49:71-75.

Duggleby W, Degner L, Williams A, Wright K, Cooper D, Popkin D, Holtslander L: Living with hope: Initial evaluation of a psychosocial hope intervention for older palliative home care patients. Journal of Pain and Symptom Management 2007, 33:247-257.

Edwards LM, Rand KL, Lopez SJ, Snyder CR: Understanding hope. In Handbook of positive psychology. Edited by: Snyder CR, Lopez SJ. New York: Oxford University Press; 2002:83-95.

Frank JD: Therapeutic factors in psychotherapy. American Journal of Psychotherapy 1971, 25:350-361.

Freud S: Psychical (or mental) treatment. In The complete psychological works of Sigmund Freud. Edited by: Strachey J. London: Hogarth Press; 281-302, (1905/1968).

Hedges LV, Olkin I: Statistical methods for meta-analysis Orlando, FL: Academic Press; 1985.

Herth KA: Enhancing hope in people with a first recurrence of cancer. Journal of Advanced Nursing 2000, 32:1431-1441.

Herth KA: Development and implementation of a hope intervention program. Oncology Nursing Forum 2001, 28:1009-1017

Hollis V, Massey K, Jevne R: An introduction to the intentional use of hope. Journal of Allied Health 2007, 36:52-56.

Huebner ES, Laughlin JE, Ash C, Gilman R: Further validation of the Multidimensional Students' Life Satisfaction Scale. Journal of Psychoeducational Assessment 1998, 16:118-134.

Hunter JE, Schmidt FL: Methods of meta-analysis: Correcting error bias in research findings Thousand Oaks, CA: Sage; 2004. 
Irving LM, Snyder CR, Cheavens J, Gravel L, Hanke J, Hilberg P, et al: The relationships between hope and outcomes at pretreatment, beginning, and later phases of psychotherapy. Journal of Psychotherapy Integration 2004, 14:419-443.

Kirschman KJB, Johnson RJ, Bender JA, Roberts MC: Positive psychology for children and adolescents: Development, prevention, and promotion. In Oxford handbook of positive psychology. Edited by: Lopez SJ, Snyder CR. New York: Oxford University Press; 2009:133-148.

Kirschman KJB, Roberts MC, Shadlow JO, Pelley TJ: An evaluation of hope following a summer camp for inner-city youth. Child Youth Care Forum 2010, 39:385-396.

Klausner EJ, Clarkin JF, Spielman L, Pupo C, Abrams R, Alexopoulos GS: Late-life depression and functional disability: The role of goal-focused group psychotherapy. International Journal of Geriatric Psychiatry 1998, 13:707-716.

Kylma J, Duggleby W, Cooper D, Molander G: Hope in palliative care: An integrative review. Palliative and Supportive Care 2009, 7:365-377

Lambert MJ, Ogles BM: The efficacy and effectiveness of psychotherapy. In Bergin and Garfield's handbook of psychotherapy and behavior change. Edited by: Lambert MJ. New York: Wiley; 2004:139-193.

Larsen DJ, Stege R: Hope-focused practices during early psychotherapy sessions. Journal of Psychotherapy Integration 2010, 20:293-311.

Layous K, Chancellor J, Lyubomirsky S, Wang L, Doraiswamy PM: Delivering happiness: Translating positive psychology intervention research for treating major and minor depressive disorders. Journal of Alternative and Complementary Medicine

Linley PA, Joseph S: Positive psychology in practice New York: Wiley; 2004.

Lipsey MW, Wilson DB: The efficacy of psychological, educational, and behavioral treatment: Confirmation from metaanalysis. American Psychologist 1993, 48:1181-1209.

Lipsey MW, Wilson DB: Practical meta-analysis Thousand Oaks, CA: Sage; 2001.

Lopez SJ, Rose S, Robinson C, Marques SC, Pais-Ribeiro J: Measuring and promoting hope is schoolchildren. In Handbook of positive psychology in schools. Edited by: Gilman R, Huebner ES, Furlong MJ. New York: Routledge; 2009:37-50.

Lopez SJ, Snyder CR, Magyar-Moe JL, Edwards LM, Pedrotti JT, Janowski K, et al: Strategies for accentuating hope. In Positive psychology in practice. Edited by: Linley PA, Joseph S, Seligman MEP. New York: Wiley; 2004:388-404.

Magyar-Moe J: Therapist's guide to positive psychological interventions New York: Elsevier; 2010

Mazzucchelli TG, Kane RT, Rees CS: Behavioral activation interventions for well-being: A meta-analysis. Journal of Positive Psychology 2010, 5:105-121.

McDermott D, Snyder CR: Making hope happen Oakland, CA: New Harbinger; 1999

McDermott D, Snyder CR: The great big book of hope Oakland, CA: New Harbinger; 2000.

McDowell CA: An exploration of the effect of imagery on hope in young stroke survivors (Dissertation). Available from ProQuest Dissertations and Theses database 2009, (UMI No. 3403392).

McNeal R, Handwerk ML, Field CE, Roberts MC, Soper S, Huefner JC, et al: Hope as an outcome variable among youths in a residential care setting. American Journal of Orthopsychiatry 2006, 76:304-311.

Menninger K: The academic lecture: Hope. American Journal of Psychiatry 1959, 109:481-491.

Nedderman AB, Underwood LA, Hardy VL: Spirituality group with female prisoners: Impacting hope. Journal of Correctional Health Care 2010, 16:117-132.

Nel J: Putting the lid on the divorce monster: Creating hope-filled narratives with storybook therapy. In Happiness, healing, enhancement: Your casebook collection for applying positive psychology in therapy. Edited by: Burns GW. Hoboken, NJ: Wiley; 2010:76-87.

Pedrotti J, Edwards L, Lopez S: Promoting hope: Suggestions for school counselors. Professional School Counseling 2008, 12:100-107.

Pretorius C, Venter C, Temane M, Wissing M: The design and evaluation of a hope-enhancing program for adults. Journal of Psychology in Africa 2008, 18:301-310.

Rand KL, Cheavens JS: Hope theory. In Oxford handbook of positive psychology. Edited by: Lopez SJ, Snyder CR. New York: Oxford University Press; 2009:323-333.

Radloff LS: The CES-D scale. Applied Psychological Measurement 1977, 1:385-401.

Ripley JS, Worthington EL: Hope-focused and forgiveness-based group interventions to promote marital enrichment. Journal of Counseling and Development 2002, 80:452-463.

Robitschek C: At-risk youth and hope. Career Development Quarterly 1996, 45:163-169.

Rosenberg M: Society and the adolescent self-image Middletown, CT: Wesleyan University Press; 1989.

Rosenthal R: The file drawer problem and tolerance for null results. Psychological Bulletin 1979, 86:638-641.

Rustoen T, Cooper BA, Miaskowski C: A longitudinal study of the effect of a hope intervention on levels of hope and psychological distress in a community-based sample of oncology patients. European Journal of Oncology Nursing 2010.

Rustoen T, Wiklund I, Hanestad BR, Torbjorn M: Nursing intervention to increase hope and quality of life in newly diagnosed cancer patients. Cancer Nursing 1998, 21:235-245.

Schrank B, Stanghellini G, Slade M: Hope in psychiatry: A review of the literature. Acta Psychiatrica Scandinavica 2008, 118:421-433.

Sin NL, Della Porta MD, Lyubomirsky S: Tailoring positive psychology interventions to treat depressed individuals. In Applied positive psychology: Improving everyday life, health, schools, work, and society. Edited by: Donaldson SI, Csikzentmihalyi M, Nakamura J. New York: Routledge; 2011:79-96.

Sin NL, Lyubomirsky S: Enhancing well-being and alleviating depressive symptoms with positive psychology interventions: A practice-friendly meta-analysis. Journal of Clinical Psychology 2009, 65:467-487.

Snyder CR: The psychology of hope New York: Free Press; 1994.

Snyder CR: Handbook of hope San Diego, CA: Academic Press; 2000

Snyder CR, Feldman DB, Taylor JD, Schroeder LL, Adams VH: The roles of hopeful thinking in preventing problems and enhancing strengths. Applied and Preventative Psychology 2000, 9:249-270.

Snyder CR, Harris C, Anderson JR, Holleran SA, Irving LM, Sigmon ST, et al: The will and the ways: Development and validation of an individual-differences measure of hope. Journal of Personality and Social Psychology 1991, 60:570-858. 
Snyder CR, Hoza B, Pelham WE, Rapoff M, Ware L, Danovsky M, et al: The development and validation of the Children's Hope Scale. Journal of Pediatric Psychology 1997, 22:399-421.

Snyder CR, Lopez SJ: Oxford handbook of positive psychology New York: Oxford University Press; 2009.

Snyder CR, Lopez SJ, Pedrotti JT: Positive psychology: The scientific and practical exploration of human strengths Thousand Oaks, CA: Sage; 2011.

Snyder CR, McDermott D, Cook W, Rapoff MA: Hope for the journey Boulder, CO: Westview Press; 1997.

Snyder CR, Parenteau SC, Shorey HS, Kahle KE, Berg C: Hope as the underlying process in the psychotherapeutic change process. International Gestalt Journal 2002, 25:11-29.

Snyder CR, Rand KL, Sigmon DR: Hope theory. In Handbook of positive psychology. Edited by: Snyder CR, Lopez SJ. New York: Oxford University Press; 2002:257-276.

Snyder CR, Sympson SC, Michael ST, Cheavens J: Optimism and hope constructs: Variants on a positive expectancy theme. In Optimism and pessimism: Implications for theory, research, and practice. Edited by: Chang EC. Washington, DC: American Psychological Association; 2001:101-125.

Snyder CR, Sympson SC, Ybasco FC, Borders TF, Babyak MA, Higgins RL: Development and validation of the state hope scale. Journal of Personality and Social Psychology 1996, 70:321-335.

Snyder CR, Taylor JD: Hope as a common factor across psychotherapy approaches: A lesson from the dodo's verdict. In Handbook of hope. Edited by: Snyder CR. San Diego, CA: Academic Press; 2000:89-107.

Spielberger CD: Manual for the State-Trait Anxiety Inventory Palo Alto, CA: Consulting Psychology Press; 1983.

Tellegen A, Watson D, Clark LA: On the dimensional and hierarchical structure of affect. Psychological Science 1999, 10:297-303.

Trump MRM: The impact of hopeful narratives on state hope, self-esteem., and state positive and negative affect on adult female survivors of incest (Dissertation). Available from ProQuest Dissertations and Theses database 1997, (UMI No. 9729080).

Turner D, Stokes L: Hope promoting strategies of registered nurses. Journal of Advanced Nursing 2006, 56:363-372.

Vernig PM: From science to practice: Bridging the gap with translational research. APS Observer 2007, 20:29-30.

Vlach AC: Effects of expressive writing exercises on measures of hope in an outpatient clinical population (Dissertation). Available from ProQuest Dissertations and Theses database 2006, (UMI No. 3259424).

Weis R, Ash SE: Changes in adolescent and parent hopefulness in psychotherapy: Effects on adolescent outcomes as evaluated by adolescents, parents, and therapists. Journal of Positive Psychology 2009, 4:356-364.

Wilson DM, Marin A, Bhardwaj P, Lichlyter B, Thurston A, Mohankumar D: A hope intervention compared to friendly visitors as a technique to reduce depression among older nursing home residents. Nursing Research and Practice 2010, 22:1-6.

Yalom ID: The theory and practice of group psychotherapy New York: Basic Books; 1995.

Ziv N, Chaim AB, Itamar O: The effect of positive music and dispositional hope on state hope and affect. Psychology of Music 2011, 39:3-17.

doi:10.1186/2211-1522-1-5

Cite this article as: Weis and Speridakos: A Meta-Analysis of hope enhancement strategies in clinical and community settings. Psychology of Well-Being: Theory, Research and Practice 2011 1:5.

\section{Submit your manuscript to a SpringerOpen ${ }^{\circ}$ journal and benefit from:}

- Convenient online submission

- Rigorous peer review

- Immediate publication on acceptance

- Open access: articles freely available online

- High visibility within the field

- Retaining the copyright to your article

Submit your next manuscript at $\boldsymbol{s p r i n g e r o p e n . c o m ~}$ 